Howes, Ellenson, et. al. Published in Journal of Drainage and Irrigation Engineering, Dec. $29,2014$.

\title{
Center Pivot Sprinkler Distribution Uniformity Impacts on the Spatial Variability of Evapotranspiration
}

\author{
Daniel J. Howes, P.E., M.ASCE${ }^{1}$; Sean Ellenson²; Lucas Hoffmann³; and Franklin Gaudi ${ }^{4}$
}

\begin{abstract}
Understanding variable evapotranspiration (ET) throughout a field can help maximize yield on a per-acre basis, as well as assist with proper irrigation scheduling. The results from this study indicate that irrigation system distribution uniformity (DU) has a significant effect on the uniformity of ET during water-stressed periods. The study site involved intensely managed forage (alfalfa and winter grain hay) irrigated by center pivots being supplied with reclaimed water near Palmdale, California. During spring and early summer 2007 the center pivots were operating under deficit irrigation. In 2010, after the installation of reservoirs, water was applied to meet full evapotranspiration $\left(\mathrm{ET}_{c}\right.$ ) demands. Using remote sensing of actual evapotranspiration, the variability in $\mathrm{ET}_{c}$ for the same pivots with the same crop was quantified. During the non-water-stressed period, ET uniformity was significantly better than during the water-stressed period (2007). The difference in uniformity was found to be attributable to irrigation system distribution uniformity. For the 540 ha used in this study, irrigation system DU was found to explain 55\% of the ET nonuniformity during deficit irrigation. A method to predict the nonuniformity in ET as a result of irrigation system DU and water-stress level is presented.
\end{abstract}

Author keywords: Irrigation systems; Evapotranspiration; Uniformity; Remote sensing.

\section{Introduction}

Uniform crop yield (in terms of both quality and quantity) is helpful for maximizing outputs with limited resources. As costs for farm inputs, such as water, fuel, fertilizers, and labor, increase, optimizing yields is of the utmost importance for farms to remain profitable. Additionally, as the world's population increases, higher yields per unit input and per cropped area will be needed to support future food, fiber, and renewable fuel demands.

Irrigation system distribution uniformity (DU) is a measure of how evenly water is applied to a crop (Burt et al. 1997). Generally, low quarter $\mathrm{DU}\left(\mathrm{DU}_{l q}\right)$ is used to quantify the measure of application evenness. $\mathrm{DU}_{l q}$ is defined as the average depth applied in the quarter of the field receiving the lowest water depth divided by the average depth applied throughout the field. DU is often presented as a fraction to prevent confusion with efficiency terms. It is impossible to have perfect DU for a variety of reasons depending on the method of irrigation. For example, center pivot sprinkler DU effects include variable pressures along the pivot, sprinkler overlap

\footnotetext{
${ }^{1}$ Assistant Professor, BioResource and Agricultural Engineering Dept., Irrigation Training and Research Center, California Polytechnic State Univ., San Luis Obispo, CA 93407 (corresponding author). E-mail: djhowes@calpoly.edu

${ }^{2}$ Graduate Student, BioResource and Agricultural Engineering Dept., California Polytechnic State Univ., San Luis Obispo, CA 93407. E-mail: sellenso@calpoly.edu

${ }^{3}$ Irrigation Support Engineer, Irrigation Training and Research Center, California Polytechnic State Univ., San Luis Obispo, CA 93407. E-mail: ljhoffma@calpoly.edu

${ }^{4}$ Lecturer, BioResource and Agricultural Engineering Dept., Irrigation Training and Research Center, California Polytechnic State Univ., San Luis Obispo, CA 93407. E-mail: fgaudi@calpoly.edu

Note. This manuscript was submitted on August 6, 2014; approved on November 10, 2014; published online on December 29, 2014. Discussion period open until May 29, 2015; separate discussions must be submitted for individual papers. This paper is part of the Journal of Irrigation and Drainage Engineering, (C) ASCE, ISSN 0733-9437/04014085(10)/\$25.00.
}

uniformity, plugging, sprinkler flow rates not proportional to area served, and sprinkler height (Burt et al. 1997). Proper design, maintenance, and management can help to maintain high DUs, which should be greater than 0.8 for center pivots.

Yield variation throughout production agricultural fields can be caused by numerous biotic and abiotic factors, including pest damage, disease, soil texture and structure differences, salinity, nutrient availability, soil compaction, edge effects, topography, and irrigation DU. For example, variation on wine grape yield (total harvested weight) has been shown to vary 8 - to 10 -fold between areas within a single field (Bramley and Hamilton 2004). Numerous studies have investigated different soil and topographic influences on the spatial uniformity of crop yield for a variety of crops (Elms et al. 2001; Kravchenko et al. 2005; Eldeiry and Garcia 2011).

Soil moisture content variation throughout fields has been shown to be highly correlated to yields in soybeans and small grains (Stafford et al. 1996; Lark and Stafford 1997; Irmak et al. 2002). Variable soil textures and structures that affected available water-holding capacities in a field under rainfed conditions where rainfall did not meet potential evapotranspiration (ET) would have an effect on yield variability that was similar to that of nonuniform irrigation with a uniform soil under deficit irrigation regimes.

Under non-water-stressed conditions, only the poorest uniformity treatment showed any impact on sugar beet yield in work done by Ayars et al. (1990). Deep percolation contributing to the saline high water table was the likely cause of this yield nonuniformity, as noted by those authors. Under both water-stressed and non-waterstressed conditions, cotton yields were more uniform with higher irrigation uniformity in California (Ayars et al. 1991). In contrast, Mateos et al. (1997) found no impact on cotton yield in Spain between different irrigation treatments and irrigation uniformities and no significant variability differences within plots. The lack of irrigation uniformity influence is likely attributed to two factors: (1) over half of the crop ET requirement was met by precipitation, which is uniformly distributed over the plot scale study; and (2) as noted by the authors, the lack of water stress during boll 
development under the nondeficit irrigation treatment resulted in fewer boll openings.

Farmers in California growing almonds, pistachios, tomatoes, and other crops frequently cite the excellent DU of irrigation water in the state as being a major contributor to higher yields. The goal of farming operations that try to maximize harvested biomass is to achieve the maximum potential yield over an entire field. Other farming operations, such as quality wine grapes or processing tomatoes, strive for an even quality of yield throughout the field. In either case, spatial uniformity of crop health is becoming more important as agriculture shifts toward the "more crop per drop" concept.

Deficit irrigation is used to improve the quality of harvested crops (e.g., wine grapes and processing tomatoes) and during drought years when farmers simply do not have enough supply to achieve optimal crop ET rates (and, by extension, yield) over the entire field. Under deficit irrigation the effects of irrigation DU could have a significant impact on yield distribution. The impact of nonuniformities in irrigation water on deficit irrigation is rarely discussed. In reality, because DU is less than 1 , some portion of the field will be under a much higher level of stress than the average and another portion may not be under stress at all.

Limited research has been conducted on the actual impact of specific factors on crop yield uniformity for deficit irrigated agriculture at the field scale. If a grower has nonuniformity and is attempting to deficit irrigate, the quality of the harvested product will vary widely.

The goal of this study was to differentiate between the impact of irrigation DU on the spatial distribution of ET from the impacts of other factors. A logical assumption is that the spatial variability of ET is directly related to the spatial variability of yield (either quantity or quality), at least within individual fields. This is well documented for alfalfa (Doorenbos and Kassam 1979; Sammis 1981; Grismer 2001), which represents over $50 \%$ of the analyzed acreage in this study.

With this assumption, the first objective of this study was to determine whether the spatial variability of ET could be measured directly using LandSAT images, courtesy of the U.S. Geological Survey, processed with Mapping EvapoTranspiration at High Resolution with Internal Calibration (METRIC) and determine whether it was different under water-stressed and non-water-stressed conditions. The second objective was to use the measured spatial distribution of ET to compute values for the actual uniformity of ET due to DU (ET_ $\left.U_{\mathrm{DU}}\right)$. The third objective was to develop a prediction of the potential nonuniformity of ET (ET_ $\left.U_{\text {DUpredicted }}\right)$ based on field-measured irrigation system DU and crop stress. It was beyond the scope of this study to conduct a detailed evaluation of soil and plant properties to quantify the individual magnitudes of nonuniformity of ET due to causes other than irrigation DU for all of the fields evaluated. However, some limited soil data collected at four locations within each field were examined and compared to the ET uniformity, as will be discussed.

\section{Study Site and Background}

In this study, an intensely managed medium-scale farming operation was examined. The agricultural site is owned and operated by County Sanitation District 20 of Los Angeles County (LACSD), Palmdale Water Reclamation Plant (WRP), which since the early 2000s has reused treated effluent to irrigate forage crops using center pivots near Palmdale, California.

The factors that make the location of this project suitable for data collection and analysis are as follows:
1. Daily water applications on a field-by-field basis are known.

2. Soil samples have been analyzed at varying locations throughout many of the fields.

3. Planting and harvest dates are known to the day, as are harvested yields (although yields were not collected spatially throughout the fields).

4. The irrigation DU of each of the center pivots is evaluated on a 1- to 2-year basis.

5. There is a known level of water stress with deficit irrigation for several years (2006-2009) on forage crops from spring to early summer because of a lack of water availability during those periods.

6. For those same center pivots, in 2010 there was no deficit irrigation in this same time frame.

The Palmdale WRP agricultural site (Fig. 1) contains 27 center pivots of varying sizes. Approximately 15 of the 27 center pivots were examined in this study. Of these, eight center pivots were planted in alfalfa from 2007 through 2010, and the remaining were used to grow winter forage (mixture of barley, wheat, and oats). The winter forage was either harvested for hay or green chopped for silage. A detailed description of the pivots and their operations can be found in Howes et al. (2007) and Gaudi et al. (2007).

An irrigation scheduling software program was developed by the primary author in 2006, through the Irrigation Training and Research Center (ITRC), for LACSD. LACSD contracted the ITRC to provide irrigation technical assistance to meet regulatory requirements to apply water at or below agronomic water rates [water to meet full ET $\left(\mathrm{ET}_{c}\right)$ and salinity leaching with a reasonable amount of deep percolation due to good irrigation distribution uniformities]. The ITRC irrigation scheduling program uses a daily soil water balance based on the FAO 56 dual-crop coefficient method (Allen et al. 1998). Weather data, grass-reference ET (ET ${ }_{o}$ ), planting and harvest dates, irrigation system DU, and center pivot flow are incorporated into the irrigation scheduling program. This information was used to predict/forecast weekly irrigation schedules and track water destinations.

Hourly and daily grass-reference ET $\left(\mathrm{ET}_{o}\right)$ and weather data were used for the irrigation scheduling program and the remote sensing portion of this study. Data were obtained from a California Irrigation Management Information System (CIMIS) weather station at the site (Palmdale Station 197). Weather data were quality controlled using methods discussed in Allen et al. (1998).

The ultimate goal of the irrigation management at this site was to consume treated wastewater (effluent) and minimize deep percolation that could carry pollutants (such as nitrate) into the groundwater. Effluent from the treatment plant was available at a relatively constant flow rate year round. Since ET rates are higher in the summer than the winter, crop acreage was increased in the winter to utilize more water. In the summer, some of the fields were fallowed to match supply with ET.

Prior to 2010, minimal effluent storage was available to regulate the supply. As ET rates increased in the spring prior to the harvest of winter forage, supplies were insufficient to meet full ET demands. This resulted in deficit irrigation each spring. After the reservoirs became operational in December 2009, winter forage acreage was reduced and excess water was stored to be used in the spring and summer to minimize deficit irrigation. Fig. 2 shows outputs of adjusted crop coefficient $\left(K_{c}\right)$ values from the irrigation program's soil water balance in a single alfalfa field in 2007 where water stress occurred [Fig. 2(a)] and in 2010 with no water stress [Fig. 2(b)].

Fig. 2 also shows the basal crop coefficient $\left(K_{c b}\right)$, precipitation, and center pivot applications. Very little precipitation occurs in this high desert area, especially in the late spring through the summer 


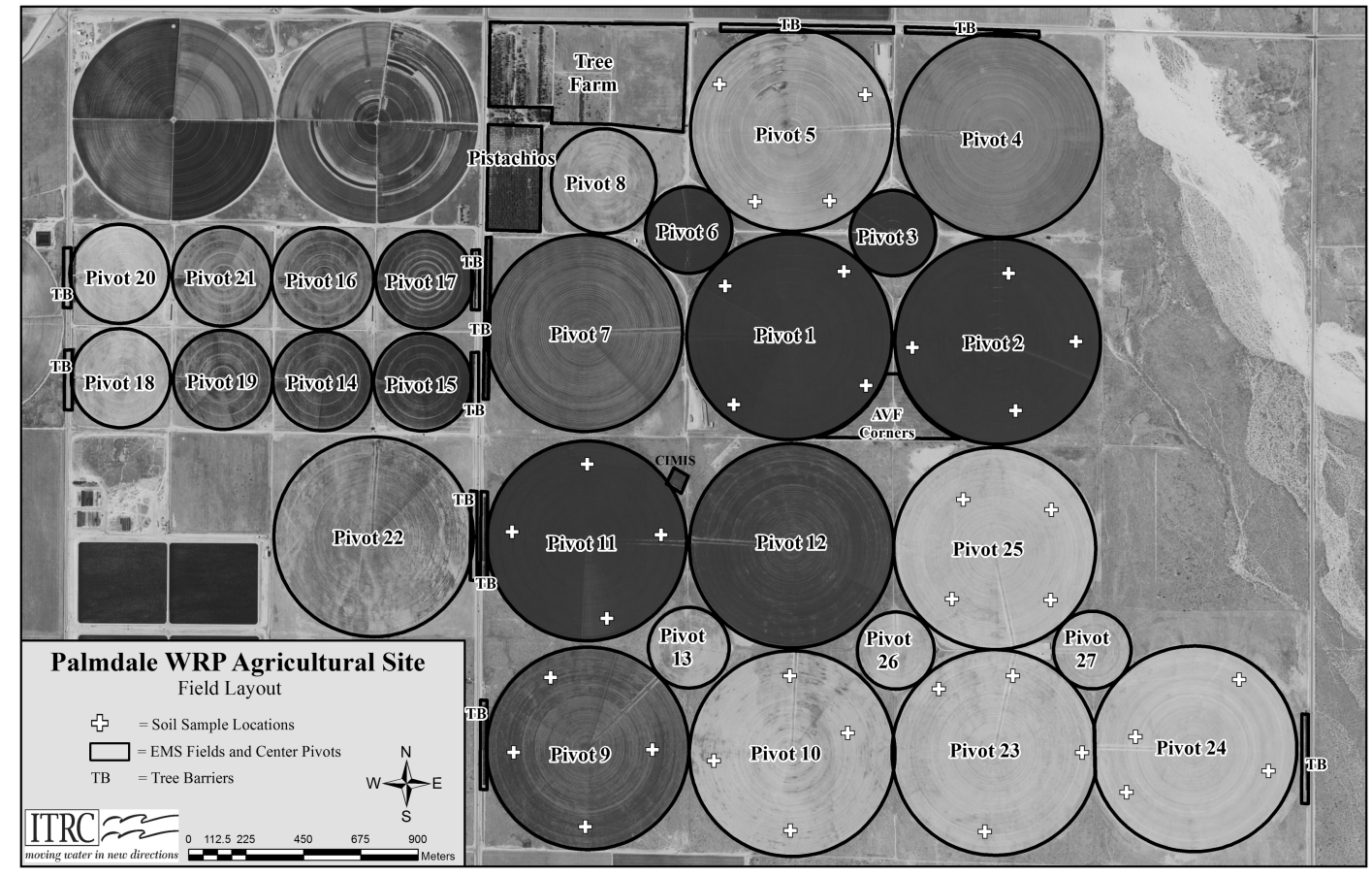

Fig. 1. Palmdale WRP Agricultural Site with a NAIP aerial photo background [reprinted from ITRC (2014), with permission; aerial photo reprinted from USDA-Farm Service Agency (FSA) (2009)]
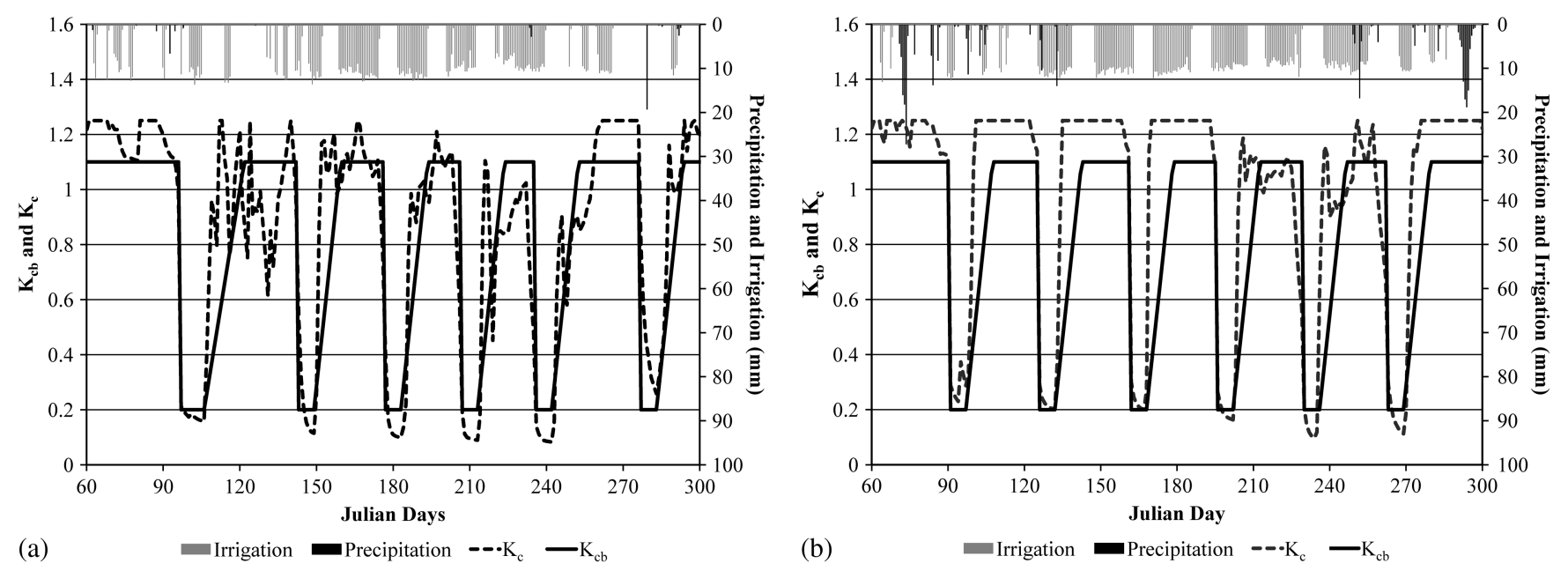

Fig. 2. Actual and basal crop coefficient ( $K_{c}$ and Basal $K_{c}$, respectively) curves for alfalfa in the same center pivot field (Pivot 1$)$ at Palmdale WRP Agricultural Sites (a) in 2007 prior to reservoir installation; and (b) in 2010 with operational reservoirs

and fall. A $K_{c}$ value above the $K_{c b}$ curve indicates soil and plant evaporation with frequent irrigations. A $K_{c}$ value below the $K_{c b}$ curve indicates likely water stress due to deficit irrigation in addition to evaporation. The cycling of the $K_{c b}$ curve indicates harvest and regrowth of the alfalfa. In this area, six to seven harvests per year are typical.

\section{Methodology}

Remote sensing was used as the primary tool for determining ET spatial variability. A total of four LandSAT 5 images were examined in this study: two from 2007 and two from 2010. The irrigation scheduling program confirmed that moderate water stress was occurring between late March and June during 2007 and that no water stress was occurring during the same time frame in 2010 in the majority of the fields. The evaluation was then focused on April and May. The image acquisition dates of April 27, 2007, May 13, 2007, April 19, 2010, and May 5, 2010 were evaluated for this project. Each image was processed using METRIC to compute instantaneous and daily $\mathrm{ET}_{c}$ as well as $K_{c}$.

METRIC is an algorithm developed by Dr. Richard Allen from the University of Idaho, in which ET is computed from LandSAT data. LandSAT satellites have a $30 \times 30 \mathrm{~m}$ resolution for nonthermal bands and $120 \times 120 \mathrm{~m}$ resolution for thermal bands (Courault et al. 2005). While several methods are available to compute ET from LandSAT data, the methodology behind METRIC, specifically within the sensible heat flux computation, was designed 
for agricultural crop ET estimation (Allen et al. 2007b). The primary author has made several modifications to the original METRIC algorithm to enhance its usability and decrease the processing time. These include developing a semiautomated calibration procedure and converting from an alfalfa-based reference ET system to a grass-based reference, which is more traditional in California.

METRIC is based on the surface energy balance equation

$$
\mathrm{LE}=R_{n}-G-H
$$

where LE = latent heat flux; $R_{n}=$ net radiation at the surface; $G=$ soil heat flux; and $H=$ sensible heat flux into the air. LE is converted into $\mathrm{ET}_{c}$ at the time the image was taken as depth per unit time (typically millimeters per hour). Each component of the surface energy balance requires numerous computations. The current model is fully described in Allen et al. (2007b, 2010).

The required information for METRIC includes LandSAT images, raster land-use maps, digital elevation models, and hourly corrected weather data from a nearby station. Utilizing image processing software ERDAS Imagine, Microsoft Excel, and ArcGIS 9.2 and 10.1, the inputs are processed and the model computes the instantaneous $\mathrm{ET}_{c}$ for each pixel within a LandSAT image. The primary models for each component of Eq. (1) are built in ERDAS Imagine. The spreadsheet program is used to compute and store parameters that are needed as inputs into ERDAS. ArcGIS is used for thermal sharpening (Trezza et al. 2008) and to create image outputs.

Hourly and daily grass-reference evapotranspiration $\left(\mathrm{ET}_{o}\right)$ and weather data were obtained from a California Irrigation Management Information System (CIMIS) weather station at the site (Palmdale Station 197). Weather data were quality-controlled using methods discussed in Allen et al. (1998). These data are used in METRIC to compute aerodynamic resistance. The instantaneous crop coefficient (instantaneous $\mathrm{ET}_{c}$ /instantaneous $\mathrm{ET}_{o}$ ) is used to estimate daily $\mathrm{ET}_{c}$ by multiplying the daily $\mathrm{ET}_{o}$ by the instantaneous $K_{c}$. Allen et al. (2007a) show that the $K_{c}$ at the instant the image is taken as a good proxy of the average daily $K_{c}$.

\section{Irrigation System Distribution Uniformity and Field Selection}

Irrigation system DU can vary widely depending on the irrigation method, system operation, and management. A full discussion of irrigation DU can be found in Burt et al. (1997). Low quarter DU $\left(\mathrm{DU}_{l q}\right)$ is commonly used to assess irrigation system performance and can be estimated as

$$
\mathrm{DU}_{l q}=\frac{\text { avg. low quarter depth }}{\text { avg. depth of water accumulated in all elements }}
$$

where the average low quarter depth is the average depth accumulated in the quarter of the area with the smallest depths. The $\mathrm{DU}_{l q}$ can be computed statistically as

$$
\mathrm{DU}_{l q}=1-1.27 \times \mathrm{CV}
$$

where $\mathrm{CV}=$ coefficient of variation computed as the standard deviation of all depths accumulated divided by the mean depth. The 1.27 in Eq. (3) is specific to $\mathrm{DU}_{l q}$. The use of Eq. (2) or (3) to assess the field $\mathrm{DU}_{l q}$ is difficult if not impossible because measuring the depth applied to all elements is infeasible. Standard measurement procedures have been established to reasonably estimate $\mathrm{DU}_{l q}$ for all irrigation types. The measurement procedure described in Burt et al. (2010) for center pivot irrigation system $\mathrm{DU}_{l q}$ was used in this study.

Because of variable harvest timing and crop rotations, not all 27 center pivot fields could be examined for both years. Some crops were harvested prior to the image acquisition date in either April or May. In some cases a different crop was planted in a field in 2010 , so those fields were not included in this evaluation. In total, 13 different fields, totaling 540 ha, were examined. Nine fields were evaluated in April, 4 different fields in May, and Pivot 5 was used for both April and May, for a total of 14 fields in this study. With the exception of Pivot 5 , the other fields could only be examined for one of the months because of the harvest schedule. Table 1 shows the field, crop type, irrigated area, and 2007 measured $\mathrm{DU}_{l q}$ for the fields used in this study.

\section{Distribution Uniformity and Evapotranspiration}

Irrigation DU can impact ET distribution, particularly during waterstressed periods. Fig. 3 shows water destination diagrams for Pivot 2 under two scenarios: (A) near-perfect irrigation scheduling with minimal water stress in 2010 (stress is limited to approximately one-eighth of the field because irrigations are scheduled based on $\mathrm{DU}_{l q}$ ) and (B) underirrigation of $100 \%$ of the field in 2007 . The plot of applied water in the last 30 days in each figure is a function of the DU, which is the same in both years $(0.83)$ and the average applied water. Note that the slope of the applied water line is different even though the DU is the same. This is due to different average depths of water applied in each pivot.

The depth of portions of the field receiving at least this amount of water was sorted from the maximum depth on the left ( $0 \%$ of the field receiving at least this amount) to the minimum depth applied in the field on the right (100\% of the field receiving at least this amount). To meet potential ET demands, more water must be applied on average so that the portion of the field receiving the least (actually the average of the lowest quarter or $87.5 \%$ point based on $\mathrm{DU}_{l q}$ ) receives at least an amount equivalent to the potential ET [Fig. 3(a)]. Otherwise, the plants are under water stress [Fig. 3(b)].

The field images beneath each water destination diagram in Fig. 3 represent the crop coefficient $\left(K_{c}\right)$ values using METRIC for each $30 \times 30 \mathrm{~m}$ pixel for Pivot 2 . The field image in Fig. 3(a) was taken May 5, 2010, and represents a non-water-stressed condition. The field image in Fig. 3(b) was taken on May 13, 2007, and shows a high water-stressed condition. Both images show alfalfa growing and were taken over 30 days from the previous harvest. Values in the water destination diagrams were estimated based on daily water meter readings over the preceding 30 days and measured irrigation DU. The potential $\mathrm{ET}_{c}$ values (dashed lines) in the destination diagrams were computed based on crop coefficients assuming no water stress and 2005 ASCE standardized

Table 1. Crop Type, Irrigated Acreage, and Measured Irrigation System Distribution Uniformity for the Fields (Center Pivots) Used in This Evaluation

\begin{tabular}{lcccc}
\hline Field & Crop type & $\begin{array}{c}\text { Irrigated } \\
\text { hectares }\end{array}$ & $\begin{array}{c}\text { Measured } \\
\mathrm{DU}_{l q}\end{array}$ & Analysis month \\
\hline Pivot 1 & Alfalfa & 51.5 & 0.87 & April \\
Pivot 2 & Alfalfa & 51.5 & 0.83 & May \\
Pivot 3 & Alfalfa & 8.9 & 0.85 & May \\
Pivot 5 & Alfalfa & 49.2 & 0.85 & April and May \\
Pivot 9 & Alfalfa & 50.6 & 0.82 & May \\
Pivot 10 & Winter forage & 50.6 & 0.85 & April \\
Pivot 11 & Alfalfa & 49.2 & 0.85 & May \\
Pivot 13 & Winter forage & 7.8 & 0.89 & April \\
Pivot 23 & Winter forage & 50.6 & 0.8 & April \\
Pivot 24 & Winter forage & 52.7 & 0.84 & April \\
Pivot 25 & Winter forage & 51.9 & 0.87 & April \\
Pivot 26 & Winter forage & 7.6 & 0.84 & April \\
Pivot 27 & Winter forage & 7.6 & 0.85 & April \\
\hline
\end{tabular}




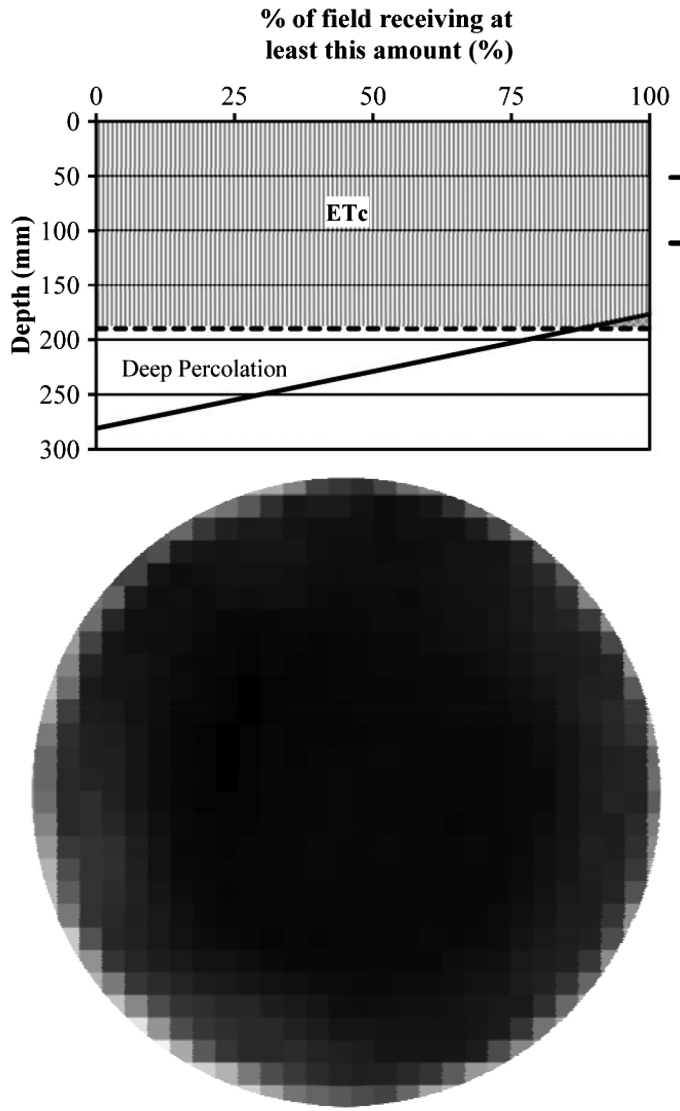

(a)

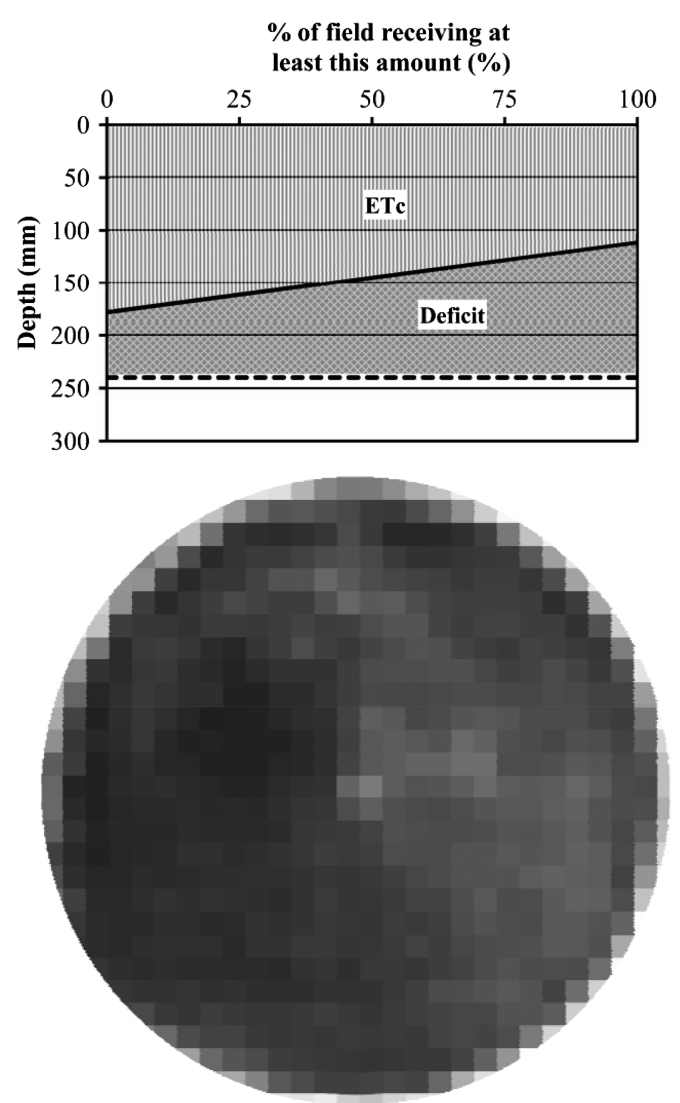

(b)

Fig. 3. Water destination diagrams (top) showing the effects of distribution uniformity on applied water under (a) perfect irrigation scheduling (May 5, 2010); and (b) underirrigation (May 13, 2007) of the field for the same field with the same DU $l q$ (0.83). METRIC images (bottom) for

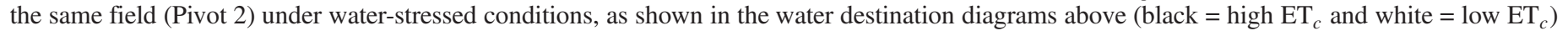

grass-reference $\mathrm{ET}\left(\mathrm{ET}_{o}\right)$ for the 30 days prior to the image date. The deep percolation is water applied in excess of $\mathrm{ET}_{c}$ but may not in fact be deep percolation. This water may be stored in the root zone for use later in the season.

Rather than analyzing $\mathrm{ET}_{c}$ uniformity to relate to field DU, the crop coefficient uniformity was used to provide a common scale to compare the two images. Actual $\mathrm{ET}_{c}$ varies with weather conditions. Using the ASCE Standardized Reference $\mathrm{ET}_{o}$ (grass/short crop) equation (Allen et al. 2005), weather conditions such as solar radiation, temperature, wind, and relative humidity were accounted for on each date. The $K_{c}$ was computed as actual $\mathrm{ET}_{c}$ divided by $\mathrm{ET}_{o}$. The $K_{c}$ uniformity is a better means for comparison because it is only based on factors such as crop type, stage of growth, and canopy coverage. Since the crop type and stage of growth are the same for each image, the higher degree of variability between the images can be attributed to higher water stress throughout the field in 2007.

Fig. 3(a) shows a well-watered condition where full potential ET demands are met throughout most of the field. In this case, there should be no spatial $K_{c}$ nonuniformity because of irrigation DU throughout the field. The METRIC-processed image below the water destination diagram in Fig. 3(a) indicates high (though not perfect) $K_{c}$ (thus $\mathrm{ET}_{c}$ ) uniformity. In any field there is some nonuniformity in ET due to other factors (ET_ $U_{\text {Other }}$ ), which is the nonuniformity apparent in Fig. 3(a). Fig. 3(b) shows underirrigation on the same parcel in 2007. In this case, the entire field is underirrigated, as indicated by the water destination diagram. The METRIC image below the water destination diagram, Fig. 3(b), shows significantly more nonuniformity in ET than the non-water-stressed condition [Fig. 3(a)]. In this water-stressed situation, METRIC shows significant ET nonuniformity well beyond $\mathrm{ET}_{-} U_{\text {Other }}$.

\section{Measured Evapotranspiration Uniformity from METRIC}

The actual computation of ET_ $U_{\text {Total }}$ and ET_ $U_{\text {Other }}$ involved extracting the ET on a pixel-by-pixel basis throughout the field using ArcGIS 10.1. The pixel statistics were extracted for each field using a polygon (circle) that was drawn inside each field with a buffer distance of $30 \mathrm{~m}$ from the edge. The buffer was used to eliminate the effects of pixels that might have overlapped the edge of the field and to decrease impacts due to edge effects. For each field in each year, the standard deviation and the mean pixel crop coefficient $\left(K_{c}\right)$ values were used to compute the coefficient of variation $(\mathrm{CV})$. A requirement for ET_ $U_{\text {Other }}$ is that the field must not be under water stress; otherwise, the irrigation system DU might affect the values.

The non-water-stressed condition was checked for the $2010 \mathrm{im}$ age dates using the dual crop coefficient soil-water-balance model, which is discussed in more detail in the next section. The model was run under three different conditions. The gross applied water is measured daily for each field. The gross applied is equivalent to the depth applied at the average point in the field. Since the irrigation system DUs in each field were measured, the amount of water applied at the points receiving the least (actually the lowest quarter) and the most, $87.5 \%$ and $0 \%$ respectively from Fig. 3, could be computed. A linear distribution between these points is assumed. The soil-water-balance model was run examining the points receiving 
the most, average, and at the lowest quarter point in the field. Water stress was likely occurring if the $\mathrm{ET}_{c}$ did not match at the average point and the lowest quarter point in the field. If this was the case in 2010, the fields were removed from the analysis.

It is assumed that the ET_ $U_{\text {Other }}$ was the same in 2010 as it was in 2007. Therefore, additional nonuniformity in ET in 2007 could be attributed to the irrigation system DU (ET_ $\left.U_{D U}\right)$. This assumption is validated in several studies. Bramley and Hamilton (2004) reported interannual variability to be similar in the same vineyards over multiple years of study. Blackmore (2000) found relatively stable interannual yield variability for wheat and oilseed rape.

The uniformity of ET within a field is estimated from these standard statistics, similar to the irrigation DU described in Burt et al. (1997) and Eq. (2) as

$$
\mathrm{ET}_{-} U_{i}=1-1.27 * \mathrm{CV}_{i}
$$

where $i$ refers to the $\mathrm{CV}$ computed from pixels in 2007 (total nonuniformity) and 2010 (nonuniformity due to other factors). The constant of 1.27 was selected to account for the lowest quarter point for the uniformity computation (similar to $\mathrm{DU}_{l q}$ ) as opposed to some other reference location. Once ET_ $U_{\text {Total }}$ and ET_ $U_{\text {Other }}$ were computed, ET_ $U_{\mathrm{DU}}$ was then directly computed, similar to a statistical procedure for defining global irrigation DU (Burt et al. 1997). The relationship between $\mathrm{ET}_{-} U_{\mathrm{Total}}, \mathrm{ET}_{-} U_{\mathrm{DU}}$, and ET_ $U_{\text {Other }}$ exists as

$$
\mathrm{ET}_{-} U_{\mathrm{Total}}=1-\sqrt{\left(1-\mathrm{ET} \_U_{\mathrm{DU}}\right)^{2}+\left(1-\mathrm{ET}_{-} U_{\mathrm{Other}}\right)^{2}}
$$

ET_ $U_{\mathrm{DU}}$ is found on a field-by-field basis by rearranging Eq. (5). The resulting ET_ $U_{\mathrm{DU}}$ is the measured uniformity of ET due to the irrigation DU from the fields in 2007.

The relative significance of ET_ $U_{\mathrm{DU}}$ compared to ET_ $U_{\text {Other }}$ on the total ET nonuniformity was examined. From Eq. (3), each of these components contributes some amount to the ET_ $U_{\text {Total }}$. The following equation was used to compute the percentage that each component contributed to ET_ $U_{\text {Total }}$ :

$$
\% \text { Contribution }=\frac{1-\mathrm{ET}_{-} U_{i}}{\left(1-\mathrm{ET} \_U_{\mathrm{DU}}\right)+\left(1-\mathrm{ET}_{-} U_{\mathrm{Other}}\right)} * 100
$$

where $\mathrm{ET}_{-} U_{i}=$ one of the two components of ET_ $U_{\text {Total }}$. The result of this will indicate the overall importance of each factor on ET and, thus, crop yield for these forage crops under water-stressed conditions.

\section{Factors Influencing $\mathrm{ET} \mathrm{U}_{\text {Other }}$}

It was beyond the scope of this study to conduct a detailed investigation of other causes of ET nonuniformity. This would have required a detailed soil sampling evaluation on a detailed grid throughout each field examined. However, soil sampling was conducted during the investigation at four locations in each of the large fields shown in Fig. 1. Samples were taken for each site at two depths $(0.25$ and $1.5 \mathrm{~m})$ and analyzed by A\&L Western Laboratories using WECA-103 testing methods (Gavlak et al. 2003). This information was used to determine whether or not a relationship exists between soil properties and ET_ $U_{\text {Other }}$ (found using the 2010 ITRC-METRIC images without the influences of water stress).

A summary of the soil properties taken from the four locations at the 0.25 and $1.5 \mathrm{~m}$ depths within each center pivot in April 2010 is shown in the supplemental Tables S1 and S2, respectively. Several statistical comparisons were made between the soil properties and variability in crop coefficients. The local average $K_{c}$ in a 40 m radius from the soil sample location normalized to the maximum $K_{c}$ in the field and a multiple regression was used to examine the influence from each of the soil properties. Additionally, the CV between sample locations within each pivot was compared to the CV of ET for that pivot using a least-squares regression. No correlation was found between soil properties and crop coefficients in either analysis, so no further discussion will be included on the topic. A more detailed soilsampling grid may have improved results; however, that type of evaluation was beyond the scope of this study.

\section{Predicted $\mathrm{ET}_{-} \mathrm{U}_{\mathrm{DU}}$ Model Based on Irrigation System Distribution Uniformity}

For each field in 2007, the ITRC irrigation scheduling software and the measured irrigation distribution uniformities were used to predict the ET_ $U_{\mathrm{DU}}$ (the predicted uniformity is termed ET_ $\left.U_{\text {DUpredicted }}\right)$.

The ET_ $U_{\text {DUpredicted }}$ was estimated by predicting the $K_{c}$ at different points in the field based on the gross water applied (average depth) and the measured irrigation system $\mathrm{DU}_{l q}$. Using Eq. (2) with the average depth applied and the $\mathrm{DU}_{l q}$, the average depth at the lowest quarter can be computed. Assuming a linear relationship between the depths accumulated, the maximum depth applied in each field can be estimated if one knows two other points on the line. The soil water balance within the irrigation scheduling program was modified to examine the depth applied at each of these three points (lowest quarter, average, and point receiving the maximum) in the field.

Fig. 4 shows several examples of the variation in $K_{c}$ relative to water applied and irrigation system DU. Pivot 5 shows stress throughout the entire field compared with Pivot 12, which shows stress only from 30 to $100 \%$ of the field. To compute ET_ $U_{\text {DUpredicted }}$, it is necessary to compute the CV. The mean and standard deviation can be computed from the equation for a line. In cases where the entire pivot is not in water stress, like Pivots 9 and 12 in Fig. 4, the slope goes to zero in the unstressed portion of the field. In these cases, equations to compute the mean and standard deviation can be separated for line segments with different slopes and combined. The slope of the linear $K_{c}$ equation for the water-stressed portion of the field, assuming water stress is occurring from 50 to $100 \%$ of the field, is

$$
m=\frac{K_{c 87.5 \%}-K_{c 50 \%}}{87.5 \%-50 \%}
$$

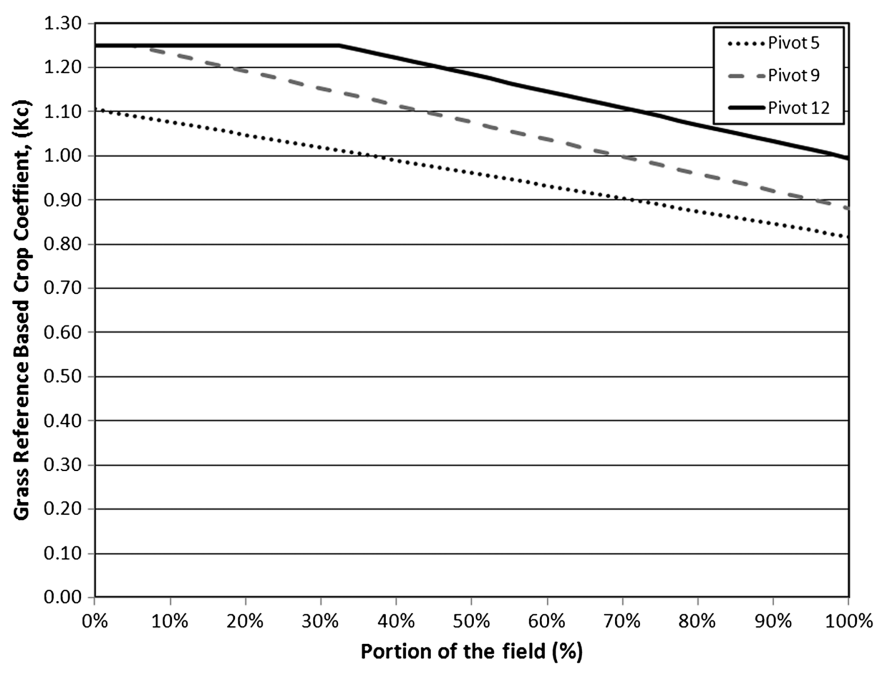

Fig. 4. Example of crop coefficients estimated at different points within a field under different water-stressed conditions 
where $K_{c 87.5 \%}$ and $K_{c 50 \%}=$ crop coefficients from soil-water balance from the lowest quarter average application and the average application points, respectively. Equations to estimate these values in lieu of a soil-water balance will be shown at a later point. The linear equation for estimating $K_{c}$ values for the portion of the field in water stress is shown as

$$
K_{c i}=m x_{i}-\frac{4}{3} K_{c 87.5 \%}+\frac{7}{3} K_{c 50 \%}
$$

where $x_{i}=$ any point (as a percentage) within the water-stressed portion of the field. The average $K_{c}$ within the water-stressed portion of the field $\left(K_{c_{-} \text {stressed_avg }}\right)$ can be computed using the average value of a function

$$
\begin{aligned}
K_{c \_ \text {stressed_avg }}= & \frac{1}{100 \%-\%_{K c \max }} \\
& \times \int_{\%_{K c \max }}^{100 \%}\left(m x-\frac{4}{3} K_{c 87.5 \%}+\frac{7}{3} K_{c 50 \%}\right) d x
\end{aligned}
$$

where $\%_{K c \text { max }}=$ portion of the field where there is no water stress, or $0 \%$, in cases where water stress occurs over the entire field. It is assumed in these sets of equations that $\%_{K c \max }$ will be between 0 and $50 \%$ of the field and that water stress is occurring on the remaining portion. In 2007, this assumption held true for all of the center pivots examined according to the soil-water balance. Integrating Eq. (9) over the interval between the $100 \%$ point and the $\%_{K c \max }$ point, and replacing $m$ with Eq. (7), the average $K_{c}$ in the stressed portion of the field ( $K_{C_{-} \text {stressed_avg }}$ ) can be computed using the simplified equation

$$
K_{c \text { stressedavg }}=\frac{100 \%\left(K_{c 50 \%}\right)-\%_{K c \max }\left(\frac{\%_{K c \max }}{75}\left(K_{c 87.5 \%}-K_{c 50 \%}\right)-\frac{4}{3} K_{c 87.5}+\frac{7}{3} K_{c 50 \%}\right)}{100 \%-\%_{K c \max }}
$$

The average $K_{c}$ in the nonstressed region is equal to $K_{c \max }$. Therefore, the field average $K_{c}$ can be computed as

$K_{c \_ \text {avg }}=\frac{K_{c_{\_} \text {stressed_avg }}\left(100 \%-\%_{K c \max }\right)+K_{c \max }\left(\%_{K c \max }-0 \%\right)}{100 \%}$

Since $K_{c \max }$ is known, $\%_{K c \max }$ can be solved for using Eq. (8), where $K_{c i}$ is set equal to $K_{c \max }$, resulting in the location, $x$, where this occurs

$$
\%_{K c \max }=\frac{37.5 \%\left(K_{c \max }+\frac{4}{3} K_{c 87.5 \%}-\frac{7}{3} K_{c 50 \%}\right)}{K_{c 87.5 \%}-K_{c 50 \%}}
$$

The standard deviation can be computed again by separating the water-stressed and non-water-stressed portions of the field. The standard deviation of the $K_{c}$ in the water-stressed portion of the field can be computed as

$$
S D_{K c_{-} \text {stressed }}=r\left(S D_{\%}\right)(m)
$$

where $r=$ correlation coefficient; $\mathrm{SD}_{\%}=$ standard deviation of the portion of the field ( $\mathrm{SD}_{\%}$ is equal to approximately 29\%); and $m=$ slope of $K_{c}$ curve from Eq. (7). Since we are solving for the standard deviation of computed values along a line, $r=1$. The standard deviation of the non-water-stressed $\left(\mathrm{SD}_{K c} \_\right.$nonstressed $)$portion of the field is equal to 0 since the $K_{c}$ in this region is assumed not to vary from the maximum. The standard deviation of the $K_{c}$ values throughout the field can be computed as

$$
\mathrm{SD}_{K c_{-} \text {field }}=\frac{\mathrm{SD}_{K c_{-} \text {stress }}\left[9900-100 \%\left(\%_{K c \max }\right)\right]}{9900}+\frac{\left[100 \%\left(\%_{K c \max }\right)-\left(\%_{K c \text { max }}\right)^{2}\right]\left(K_{c_{-} \text {stress_avg }}-K_{c_{-} \max }\right)^{2}}{9900}
$$

The CV can then be computed as

$$
\mathrm{CV}=\frac{\mathrm{SD}_{K c_{-} \text {field }}}{K_{c_{-} \text {avg }}}
$$

The ET_ $U_{\text {DUpredicted }}$ was then computed using Eq. (4). The critical piece of this procedure to estimate ET_ $U_{\text {DU_predicted }}$ is determining $K_{c 50 \%}$ and $K_{c 87.5 \%}$. If $K_{c 50 \%}$ is known, likely from some type of soil-water-balance modeling, and water stress is occurring in the lowest half of the field, then $K_{c 87.5 \%}$ can be estimated as

$$
K_{c \_87.5 \%}=\mathrm{DU}_{l q}\left(K_{c \_50 \%}\right)
$$

If $K_{c 50 \%}$ is unknown, then it can be estimated if the amount of deficit irrigation is known or can be predicted. Irrigations scheduled using regulated deficit irrigation will reduce $\mathrm{ET}_{c}$ by a certain percentage as a target. This will ideally occur at the average point in the field. Therefore, $K_{c 50 \%}$ can be estimated as

$$
K_{c_{-} 50 \%}=\frac{(\mathrm{RDI} \%)}{100 \%}\left(K_{c_{-} \text {full }}\right)
$$

where $\mathrm{RDI} \%=$ percentage of full $\mathrm{ET}_{c}$ [e.g., $\mathrm{RDI} \%$ of $100 \%$ is full $\mathrm{ET}_{c}$ and no water stress, compared to an RDI\% of $60 \%$, which results in a $40 \%$ reduction in $\mathrm{ET}_{c}$ at the target point (50\% point)].

When using RDI strategies, the irrigation system DU should not be used to determine a gross amount applied (however, if RDI is not employed, then DU should be used to adjust the net plant requirement to the gross irrigation requirement to ensure that the entire field is fully irrigated). The reason the gross irrigation requirement should be equal to the net plant requirement target stems from the fact that on average over the entire field, the $\mathrm{ET}_{c}$ will be reduced 
Table 2. Field Mean, Standard Deviation, and Coefficient of Variation of the Crop Coefficient, and ET_U from METRIC Processed Images

\begin{tabular}{|c|c|c|c|c|c|c|c|c|c|c|}
\hline \multirow[b]{3}{*}{ Month } & \multirow[b]{3}{*}{ Pivot } & \multicolumn{4}{|c|}{2007} & \multicolumn{4}{|c|}{2010} & \multirow{3}{*}{$\begin{array}{l}2007 \\
\text { ET_ } U_{\mathrm{DU}}\end{array}$} \\
\hline & & \multicolumn{3}{|c|}{$K c$} & \multirow[b]{2}{*}{ ET_ $U_{\text {Total }}$} & \multicolumn{3}{|c|}{$K c$} & \multirow[b]{2}{*}{ ET_$U_{\text {Other }}$} & \\
\hline & & Mean & SD & $\mathrm{CV}$ & & Mean & SD & $\mathrm{CV}$ & & \\
\hline \multirow[t]{9}{*}{ April } & 1 & 0.80 & 0.11 & 0.132 & 0.832 & 1.10 & 0.07 & 0.065 & 0.917 & 0.854 \\
\hline & 5 & 0.94 & 0.11 & 0.119 & 0.849 & 1.22 & 0.07 & 0.056 & 0.929 & 0.867 \\
\hline & 10 & 0.96 & 0.15 & 0.153 & 0.806 & 1.06 & 0.11 & 0.099 & 0.874 & 0.852 \\
\hline & 13 & 0.88 & 0.08 & 0.086 & 0.890 & 0.89 & 0.07 & 0.074 & 0.906 & 0.943 \\
\hline & 23 & 1.10 & 0.16 & 0.148 & 0.812 & 1.20 & 0.09 & 0.075 & 0.905 & 0.838 \\
\hline & 24 & 1.04 & 0.10 & 0.100 & 0.874 & 1.16 & 0.08 & 0.065 & 0.917 & 0.904 \\
\hline & 25 & 1.17 & 0.09 & 0.075 & 0.905 & 1.21 & 0.07 & 0.055 & 0.930 & 0.936 \\
\hline & 26 & 1.09 & 0.08 & 0.075 & 0.904 & 0.90 & 0.06 & 0.070 & 0.911 & 0.964 \\
\hline & 27 & 0.96 & 0.14 & 0.145 & 0.816 & 1.16 & 0.06 & 0.048 & 0.939 & 0.827 \\
\hline \multirow[t]{7}{*}{ May } & 2 & 0.84 & 0.10 & 0.115 & 0.854 & 1.13 & 0.08 & 0.069 & 0.912 & 0.883 \\
\hline & 3 & 0.86 & 0.09 & 0.110 & 0.860 & 1.08 & 0.06 & 0.058 & 0.926 & 0.881 \\
\hline & 5 & 1.01 & 0.09 & 0.091 & 0.884 & 1.22 & 0.07 & 0.056 & 0.929 & 0.909 \\
\hline & 9 & 0.83 & 0.09 & 0.105 & 0.866 & 0.91 & 0.07 & 0.081 & 0.897 & 0.914 \\
\hline & 11 & 1.01 & 0.13 & 0.125 & 0.842 & 1.13 & 0.08 & 0.073 & 0.908 & 0.871 \\
\hline & Mean $^{a}$ & 0.96 & 0.11 & 0.113 & $0.857 \mathrm{a}$ & 1.10 & 0.07 & 0.067 & $0.914 b$ & 0.889 \\
\hline & SD & 0.11 & - & - & 0.033 & 0.12 & - & - & 0.017 & 0.041 \\
\hline
\end{tabular}

Note: $\mathrm{CV}=$ coefficient of variation; $K_{c}=$ crop coefficient; $\mathrm{SD}=$ standard deviation.

${ }^{\mathrm{a}}$ The a and b next to mean ET_ $U_{\text {Total }}$ and ET_ $U_{\text {Other }}$ indicate significant difference at a $99 \%$ level $(p<0.01)$ using a paired t-test.

by some percentage. If the irrigation system DU is included in the irrigation system requirement, the only point in the field where the target $\mathrm{ET}_{c}$ rate will occur is at the $87.5 \%$ point. This would result in an $\mathrm{ET}_{c}$ above the target on $87.4 \%$ of the field, an $\mathrm{ET}_{c}$ below the target on $12.4 \%$ of the field, and an average $\mathrm{ET}_{c}$ well above the target. In cases where net is equal to gross application, the target $\mathrm{ET}_{c}$ will be met at the $50 \%$ point. In this case, $49.9 \%$ of the field has an $\mathrm{ET}_{c}$ above the target, $49.9 \%$ of the field has an $\mathrm{ET}_{c}$ below the target, and on average the field has the target $\mathrm{ET}_{c}$.

\section{Statistical Methods}

The mean ET_ $U_{\text {Total }}$ and ET_ $U_{\text {Other }}$ over all pivots were compared using a paired t-test to ensure a significant difference (rejecting the null hypothesis that the means are equal). By rejecting the null hypothesis, it can be concluded that irrigation system uniformity had an impact on ET nonuniformity. The resulting ET_ $U_{\text {Total }}$ and ET_ $U_{\text {Other }}$ were tested for normality and equal variance to ensure that these assumptions were met for the paired t-test. Percentage error was used to examine and compare the ET_ $U_{\text {DUpredicted }}$ and the measured ET_ $U_{\mathrm{DU}}$ for each of the fields examined in 2007.

\section{Results}

Table 2 shows the mean, standard deviation, and the coefficient of variation of the crop coefficient $\left(K_{c}\right)$ from the ET images created using the ITRC-METRIC process. The resulting ET_ $U_{\text {Total }}$ and ET_ $U_{\text {Other }}$, based on Eq. (4), are shown for each center pivot. For this analysis to be effective, the ET_ $U_{\text {Other }}$ must be greater than the ET_ $U_{\text {Total }}$. The mean ET_ $U_{\text {Total }}$ and ET_ $U_{\text {Other }}$ of 0.857 and 0.914 , respectively, were found to be significantly different at the $99 \%$ confidence level. This provides strong evidence that ET uniformity is influenced by the irrigation system DU when the field is deficit irrigated.

Using the values of ET uniformity, measured ET_ $U_{\text {DU }}$ was computed using Eq. (5) under the 2007 water-stressed conditions and is shown in the last column of Table 2. The mean ET_ $U_{\text {DU }}$ is lower than the mean ET_ $U_{\text {Other }}$, although this is not the case for all fields. This indicates that irrigation system DU has a more significant impact on the nonuniformity of ET in a field compared to other factors. Incorporating the mean $\mathrm{ET}_{-} U_{\mathrm{DU}}$ and $\mathrm{ET}_{-} U_{\mathrm{Other}}$ into Eq. (6), for these fields under water-stressed conditions, the irrigation DU has a $55 \%$ influence on the nonuniformity of ET compared to $45 \%$ due to "other" factors. Interestingly, this is similar to the effects of soil available water on yield in nonirrigated soybeans found by Irmak et al. (2002). In nonirrigated conditions, variable soil water contents due to a variety of factors, including soil type and structure, should have effects similar to those of irrigation DU under water-stressed conditions.

The importance of quantifying $\mathrm{ET}_{-} U_{\mathrm{DU}}$ is in understanding its significance related to the overall uniformity in crop ET and the impact on yield. Since vegetative crops, such as the winter forage and alfalfa examined here, typically have yields that are directly proportional to the ET, the irrigation system DU will have a significant impact on yield.

\section{ET_U Dupredicted Model}

The irrigation system DU and the values from the soil-water balance were used to compute the ET_ $U_{\text {DUpredicted }}$ using the procedures

Table 3. Comparison of ET_ $\mathrm{U}_{D U}$ Computed from the ITRC-METRIC Evaluation and ET_U $U_{\text {DUpredicted }}$ Based on Irrigation System DU and Soil Water Balance Modeling

\begin{tabular}{lcccr}
\hline Month & Pivot & ET_ $U_{\text {DU }}$ & ET_ $U_{\text {DU }}$ predicted & Error $(\%)$ \\
\hline April & 1 & 0.854 & 0.872 & 2.2 \\
& 5 & 0.873 & 0.853 & -2.4 \\
& 10 & 0.852 & 0.853 & 0.1 \\
& 13 & 0.943 & 0.955 & 1.3 \\
& 23 & 0.838 & 0.826 & -1.4 \\
& 24 & 0.903 & 0.851 & -5.7 \\
& 25 & 0.936 & 0.887 & -5.2 \\
& 26 & 0.964 & 0.883 & -8.4 \\
May & 27 & 0.827 & 0.853 & 3.2 \\
& 2 & 0.883 & 0.843 & -4.6 \\
& 3 & 0.881 & 0.853 & -3.3 \\
& 5 & 0.909 & 0.853 & -6.2 \\
& 9 & 0.914 & 0.906 & -0.9 \\
& 11 & 0.871 & 0.876 & 0.5 \\
& Mean & 0.889 & 0.869 & -2.2 \\
\hline
\end{tabular}




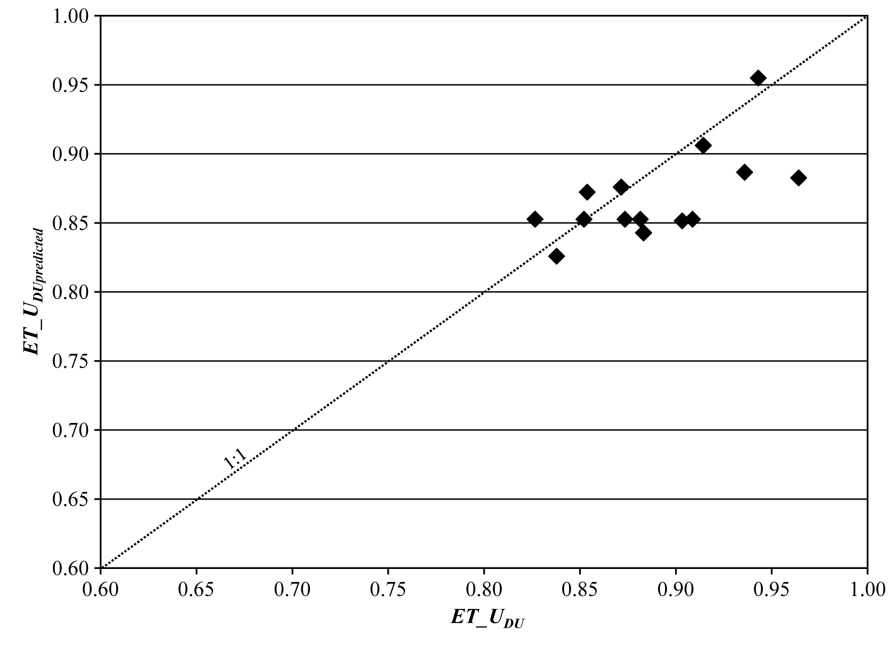

Fig. 5. Relationship between $\mathrm{ET} \_U_{\text {DUpredicted }}$ and ET_ $U_{\mathrm{DU}}$ (measured) under deficit irrigation showing the 1:1 line as reference

previously described [Eq. (4) and Eqs. (7)-(14)]. The results and percentage error compared to the ET_ $U_{\mathrm{DU}}$ are shown in Table 3. The average ET_ $U_{\mathrm{DU}}$ and ET_ $U_{\text {DUpredicted }}$ were 0.89 and 0.87 , respectively. The percentage error was $-2.2 \%$, indicating that the ET_ $U_{\text {DUpredicted }}$ would slightly overestimate the effect of irrigation system DU on ET nonuniformity.

There could be several reasons why the predicted and actual ET_ $U_{\text {DU }}$ are different. The methodology described in Eqs. (7)-(17) assumes that the same points in the field are always receiving the same portion of the gross applied water (i.e., the $100 \%$ point in the field is always the same and always receiving the least amount of water). For certain irrigation systems, such as drip and microspray, this is a reasonable assumption because the main contributors to nonuniformity are plugging and pressure differences. Pressure differences should be consistent at each irrigation so that the same portion of the field should be the area receiving the least amount of water. Sprinkler systems, however, have an additional component of DU: sprinkler overlap (catch-can uniformity). Because of wind effects, catch-can uniformity could vary from irrigation to irrigation, changing the amount of water that might be applied to each given point. Because pressure differences will continue to be a major factor, the effects would be relatively minor but nevertheless could factor into the results.

Fig. 5 shows the relationship between the ET_ $U_{\text {DU }}$ from Table 3 and predicted ET_ $U_{\mathrm{DU}}$. The 1:1 line is shown as a reference. The least-squares regression (not shown) has an $r^{2}=0.41(p=0.013)$. One likely reason for the low $r^{2}$ was previously explained. Another potential reason for the discrepancy and lower ET_ $U_{\text {DUpredicted }}$ is an effect of irrigation system DU on our ET_ $U_{\text {other }}$ estimate. The center pivot irrigation schedule at this site, based on the ITRC irrigation scheduling program, was based on the gross water requirement computed with $\mathrm{DU}_{l q}$ measurements. This should result in one-eighth of the field being underirrigated. Therefore, the ET_ $U_{\text {other }}$ obtained from the variation in ET during the non-waterstressed year (2010) could be lower than estimated. That would mean that irrigation system DU could be a factor in $\mathrm{ET}_{-} U_{\text {other }}$ and that this value could be higher. If this is the case, it could mean that the contribution of irrigation system DU on ET nonuniformity is actually greater than $55 \%$ in these fields under deficit irrigation.

The assumption of linearity of DU in the prediction method may have influenced the lack of correlation. If the uniformity is higher in the portion of the field receiving more water, this would have resulted in more uniform ET than predicted.
It should be noted that the irrigation system DUs for the center pivots are considered good to very good $(0.8-0.89)$. This results in a relatively tight grouping since the variation in $\mathrm{ET}_{-} U_{\mathrm{DU}}$ (predicted and measured) is within approximately 0.15 .

\section{Application}

While the predicted ET_ $U_{\mathrm{DU}}$ tended to overestimate the impacts of irrigation system DU compared with measured values, the prediction method allows a user to estimate the influence of system DU on ET variability. Evapotranspiration can be used to estimate crop yield, using relative ET-relative yield relationships (Doorenbos and Kassam 1979). Since relative ET is equivalent to relative crop coefficients (because $\mathrm{ET}_{\text {actual }}$ and $\mathrm{ET}_{\text {potential }}$ are equal to $K_{c_{-} \text {actual }} * \mathrm{ET}_{o}$ and $K_{c_{-} \text {potential }} * \mathrm{ET}_{o}$, respectively), the average field crop coefficient can be determined using Eqs. (10)-(12) and Eqs. (16) and (17).

It must be noted that this procedure will show little improvement in yield quantity if the entire field is deficit irrigated (no portion of the field is receiving full water supply). The reason for this is that the average crop coefficient will be the same even with an improved irrigation system DU. Simply put, improving DU in this case evens out the applied water, which would increase the stress in the portion of the field that was receiving more water and decrease the stress in the portion receiving less water. However, excessive stress in portions of the field can be detrimental to plants beyond that shown in the relative ET-relative yield relationships. Yield may not be influenced by DU computationally, and excessive water stress can lead to a number of issues, including premature alfalfa stand degradation or stress-induced dormancy. On the other side of the water destination diagram, excessive water supply can create or increase the potential for water logging, nematode problems, and root diseases.

If crop quality is the major consideration, as opposed to biomass quantity, under whole field deficit irrigation, improving DU will improve yield quality. As previously discussed, a very good irrigation system DU combined with proper irrigation scheduling can lead to improved sugar content in grapes, induce boll formation in cotton, and increase soluble solid concentration for processing tomatoes.

\section{Conclusion}

Utilizing LandSAT images with the METRIC algorithm, this study examined the spatial variability in $\mathrm{ET}_{c}$ for forage crops (alfalfa and winter forage) being irrigated with center pivots under waterstressed and non-water-stressed situations. The results from this study show that under water-stressed conditions, the ET_ $U_{\mathrm{DU}}$ contributed approximately $55 \%$ to the overall nonuniformity of ET in the fields evaluated. This highlights the importance of designing for and maintaining good irrigation DU.

A method of predicting the nonuniformity in ET based on the level of water stress (RDI\%) and the irrigation system DU is presented. The average bias toward overprediction over all pivots was only $-2.2 \%$. The authors believe the method for predicting the variability due to DU can provide reasonable estimates and justification for improving irrigation system DU to improve yields (yields for quality or quantity) through improvements in ET uniformity.

The significant contribution of DU to ET variability warrants further investigation into this area. This might include correlating ET variability, crop yield variability, and irrigation system DU. Additionally, the prediction method provided here could be used by researchers to discount the DU effects and better quantify the components of nonuniformity due to other causes, for example, variability in soil types, salinity, and topography. 


\section{Acknowledgments}

This work was supported by a grant from the California State University Agricultural Research Institute (47851). We gratefully acknowledge support from County Sanitation Districts of Los Angeles County for in-field data collection and monitoring.

\section{Supplemental Data}

Tables S1 and S2 are available online in the ASCE Library (www .ascelibrary.org).

\section{References}

Allen, R. G., et al., eds., (2005). The ASCE standardized reference evapotranspiration equation, ASCE, Reston, VA.

Allen, R. G., et al. (2007a). "Satellite-based energy balance for mapping evapotranspiration with internalized calibration (METRIC)applications." J. Irrig. Drain. Eng., 10.1061/(ASCE)0733-9437 (2007)133:4(395), 395-406.

Allen, R. G., Pereira, L. S., Raes, D., and Smith, M. (1998). "Crop evapotranspiration: Guidelines for computing crop water requirements." FAO Irrigation and Drainage Paper 56, Food and Agricultural Organization of the United Nations, Rome.

Allen, R. G., Tasumi, M., Trezza, R., and Kjaersgaard, J. (2010). Mapping evapotranspiration at high resolution: Application manual for LandSAT imagery, Univ. of Idaho, Kimberly, ID, 248.

Allen, R. G., Trezza, R., and Tasumi, M. (2007b). "Satellite-based energy balance for mapping evapotranspiration with internalized calibration (METRIC)-model.” J. Irrig. Drain. Eng., 10.1061/(ASCE)0733-9437 (2007)133:4(380), 380-394.

ArcGIS 9.2 and 10.1 [Computer software]. Redlands, CA, Esri.

Ayars, J. E., Hutmacher, R. B., Hoffman, G. J., Letey, J., Ben-Asher, J., and Solomon, K. H. (1990). "Response of sugar beet to non-uniform irrigation.” Irrigation Science, 11(2), 101-109.

Ayars, J. E., Hutmacher, R. B., Vail, S. S., and Schoneman, R. A. (1991). "Cotton response to nonuniform and varying depths of irrigation." Agric. Water Manage., 19(2), 151-166.

Blackmore, S. (2000). "The interpretation of trends from multiple yield maps." Comput. Electron. Agric., 26(1), 37-51.

Bramley, R., and Hamilton, R. (2004). "Understanding variability in winegrape production systems." Aust. J. Grape Wine Res., 10(1), 32-45.

Burt, C., Walker, R., Styles, S., and Parrish, J. (2010). Irrigation evaluations, Irrigation Training and Research Center, California Polytechnic State Univ., San Luis Obispo, CA.

Burt, C. M., et al. (1997). "Irrigation performance measures: Efficiency and uniformity." J. Irrig. Drain. Eng., 10.1061/(ASCE)0733-9437(1997) 123:6(423), 423-442.

Courault, D., Seguin, B., and Olioso, A. (2005). "Review on estimation of evapotranspiration from remote sensing data: From empirical to numerical modeling approaches." Irrig. Drain. Syst., 19(3), 223-249.
Doorenbos, J., and Kassam, A. H. (1979). "Yield response to water." FAO Irrigation and Drainage Paper 33, Food and Agriculture Organization of the United Nations, Rome.

Eldeiry, A. A., and Garcia, L. A. (2011). "Using indicator kriging technique for soil salinity and yield management." J. Irrig. Drain. Eng., 10.1061/ (ASCE)IR.1943-4774.0000280, 82-93.

Elms, M. K., Green, C. J., and Johnson, P. N. (2001). "Variability of cotton yield and quality." Commun. Soil Sci. Plant Anal., 32(3-4), 351-368.

Erdas Imagine 2011 [Computer software]. Atlanta, GA, Earth Resource Data Analysis System.

Gaudi, F., Howes, D., and Ton, D. (2007). "Center pivot design for effluent irrigation of agricultural forage crops." Proc., Irrigation Association 28th Annual Int. Irrigation Show, Irrigation Association, Falls Church, VA, 16.

Gavlak, R., Horneck, D., Miller, R. O., and Kotuby-Amacher, J. (2003). "Soil, plant and water reference methods for the western region." WREP-125, 2nd Ed., WERA-103 Publication, Colorado State Univ., Fort Collins, CO.

Grismer, M. (2001). "Regional alfalfa yield, ETc, and water value in western states." J. Irrig. Drain. Eng., 10.1061/(ASCE)0733-9437 (2001)127:3(131), 131-139.

Howes, D., Gaudi, F., and Ton, D. (2007). "Effluent nitrogen management for agricultural re-use applications." Proc., Irrigation Association 28th Annual Int. Irrigation Show, Irrigation Association, Falls Church, VA, 12 .

Irmak, A., et al. (2002). "Relationship between plant available soil water and yield for explaining soybean yield variability." Appl. Eng. Agric., 18(4), 471.

ITRC (Irrigation Training and Research Center). (2014). 〈www.itrcweb .org . (Jul. 10, 2014).

Kravchenko, A. N., Robertson, G. P., Thelen, K. D., and Harwood, R. R. (2005). "Management, topographical, and weather effects on spatial variability of crop grain yields." Agron. J., 97(2), 514-523.

Lark, R. M., and Stafford, J. V. (1997). "Classification as a first step in the interpretation of temporal and spatial variation of crop yield." Ann. Appl. Biol., 130(1), 111-121.

Mateos, L., Mantovani, E. C., and Villalobos, F. J. (1997). "Cotton response to non-uniformity of conventional sprinkler irrigation." Irrig. Sci., 17(2), 47-52.

Sammis, T. W. (1981). "Yield of alfalfa and cotton as influenced by irrigation." Agron. J., 73(2), 323-329.

Stafford, J. V., Ambler, B., Lark, R. M., and Catt, J. (1996). "Mapping and interpreting the yield variation in cereal crops." Comput. Electron. Agric., 14(2-3), 101-119.

Trezza, R., et al. (2008). "Enhanced resolution of evapotranspiration from riparian systems and field edges by sharpening the Landsat thermal band." Proc., World Environmental and Water Resources Congress, Vol. 316, ASCE, Reston, VA, 98-98.

USDA-Farm Service Agency (FSA). (2009). NAIP aerial photograph of Los Angeles county (ortho_1-2_1n_s_ca037_2009_1), USDA FSA Aerial Photography Field Office, Salt Lake City. 